\title{
Researches of the combined coulter working process for direct strip sowing of seeds
}

\author{
Victor Khamuev ${ }^{1, *}$, Oleg Pisarev², Andrey Boiko ${ }^{3}$, and Dmitriy Podlesniy ${ }^{3}$ \\ ${ }^{1}$ Federal Scientific Agro-Engineering Center VIM, 1 Institutsky proezd, 5, Moscow, 109428, Russia \\ ${ }^{2}$ LLC Polivproekt, Cosmonauts Avenue, 15, room CLII, Korolev city, Moscow Region 141075,Russia \\ ${ }^{3}$ Don State Technical University, Gagarin Square, 1, Rostov-on-Don, 344000, Russia.
}

\begin{abstract}
In this paper We presented design of analytic dependencies of main geometrics parameters of combine coulter distributer for direct strip sowing of cereals with accounting of pass speed of particle from the distributer.
\end{abstract}

\section{Introduction}

More perspective direction for conditions of the Russian Federation is development seeder of direct sowing with passive working bodies if we will take in account higher reliability in working, relatively simple construction and accordingly, the lower cost in manufacturing and in purchasing by the agricultural producer. At the same time, combined working bodies for direct sowing of cereals are perspective. They ensure the uniform distribution of seeds over the feeding area. Researches of justification of the main parameters of the combined coulter of the direct sowing seeder are actual tasks especially for ensuring high-quality strip sowing of cereals in compliance with agrotechnical requirements for zero tillage [1-6].

\section{Material and methods}

In the strip sowing, one part of the seeds enters to the soil through the seed tube 2 in the central part of the coulter, and other seeds scatter across the soil with a distributor in duckfoot sweep 1, which forms the seeding strip Figure. 1.

For this function, It is necessary to find the geometric correlation between the constructions elements of the distributor for a given sowing strip width $b_{n}$, the transverse dimensions of the seed tube outlet pipe: length $L_{c}$ and width $b_{c}$, dihedral angle $2 \gamma$ at the top of the distributor, clearance $\Delta \mathrm{h}$ between the lower edge of the distributor and the soil , subsweep height $\mathrm{H}_{\mathrm{c}}$ Figure. 2.

We chose such defined parameters of the distributor: the distributor width $\left(b_{p}\right.$, the length of the rectilinear section of the distributor surface $L_{n}=A B$, the length of the curved section of

\footnotetext{
* Corresponding author: victor250476@yandex.ru
} 
the distributor surface $\mathrm{L}_{K}=\mathrm{BC}$, the radius of the curvilinear area circle of the distributor surface $\mathrm{R}$, the angle of inclination of the edge $\delta$ to the longitudinal axis of the coulter, central angle $\alpha$ of the generatrix of the curvilinear area, the height of the distributer top $\mathrm{Hp}$, the distance $h_{o}$ from the soil surface of the center of the circle of the curvilinear area of the distributor surface (point $\mathrm{O}$ ) and the distance $\mathrm{l}_{\mathrm{o}}$ from distributor axis to the specified center.

It was made mathematical analysis of the association of the geometric distributor parameters in accordance with the calculation scheme. Figure. 2.

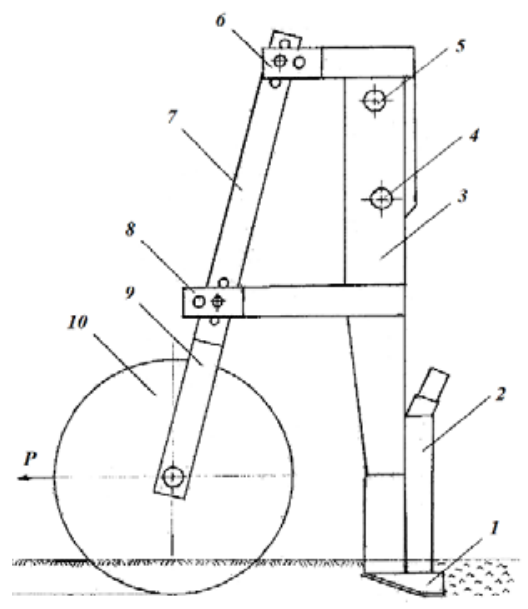

Fig. 1. Combined coulter scheme: 1 is duckfoot sweep; 2 is seed tube; 3is opener stand; 4,5 are hole for mounting the coulter; 6, 8 are mounts for a circular knife; 7 is stand of a circular knife; 9 is a fork of a stand of a disk knife; 10 is circular knife.
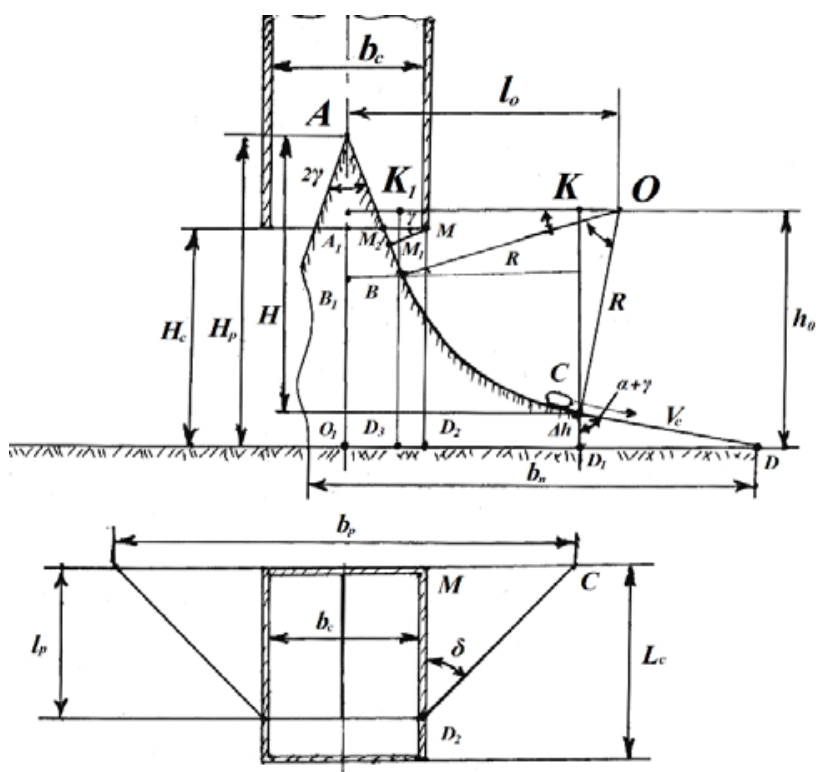

Fig. 2. The calculation scheme for justification of the distributor geometric parameters 


\section{Results and discussion}

Space between the rectilinear area $\mathrm{AB}$ and the seed tube can be selected according taking into account the grain particle length, i.e. $\mathrm{M}_{1} \mathrm{M}=\mathrm{l}_{\mathrm{z}}$., for free passage of a grain particle with length $\mathrm{l}_{\mathrm{z}}$ to a curved linear area of the BC surface. Then the horizontal projection $\mathrm{MM}_{2}$ of the indicated segment from $\Delta \mathrm{MM}_{1} \mathrm{M}_{2}$ is equal to

$$
M M_{2}=\frac{l_{z}}{\cos \gamma} .
$$

According this, the magnitude of the horizontal projection of the rectilinear generatrix area $\mathrm{AM}_{2}$, is determine by equation (2), which located inside the seed tube

$$
A_{1} M_{2}=\frac{b_{c}}{2}-\frac{l_{z}}{\cos \gamma}=\frac{b_{c} \cos \gamma-2 l_{z}}{2 \cos \gamma},
$$

And Its vertical projection - interval $\mathrm{AA}_{1}$, is equael:

$$
A A_{1}=\frac{A_{1} M_{2}}{\operatorname{tg} \gamma}=\frac{b_{c} \cos \gamma-2 l_{z}}{2 \sin \gamma} .
$$

Then distance from the distributor top (point A) to the soil surface is determining by dependence:

$$
H_{p}=H_{c}+A A_{1}=\frac{2 H_{c} \sin \gamma+b_{c} \cos \gamma-2 l_{z}}{2 \sin \gamma} .
$$

$\mathrm{B} \triangle \mathrm{CD}_{1} \mathrm{D}$ hypotenuse of the $\mathrm{SD}$ is coinciding with the particle flight trajectory when its leaving the distributor at the speed $\mathrm{V}_{\mathrm{c}}$. With this in mind, the particle motion time $\mathrm{t}_{\mathrm{z}}$ can be determined according to the free-fall law of a moving particle from the height of SD1 $=\Delta \mathrm{h}$ in the SD section.

From the physics course it is known that in this case $\Delta h=\frac{g t_{z}^{2}}{2}$, from $t_{z}=\sqrt{\frac{2 \Delta h}{g}}$, and

$$
C Д=V_{c} t_{z}=V_{c} \sqrt{\frac{2 \Delta h}{g}} .
$$

From the triangle $\triangle \mathrm{DSD} 1$ it follows that:

$$
\Delta h=С Д \cos \angle Д С Д_{1}=V_{c} \cos \angle Д C Д_{1} \sqrt{\frac{2 \Delta h}{g}} .
$$

But from a comparison of the angles $\llcorner$ СОК and $\llcorner Д С Д 1$ it follows that $\angle D C C_{1}=\alpha+\gamma$, therefore, taking into account (6)

$$
\cos (\alpha+\gamma)=\frac{\Delta h}{V_{c} \sqrt{\frac{2 \Delta h}{g}}}=\frac{\sqrt{2 g \Delta h}}{2 V_{c}},
$$

and 


$$
\sin (\alpha+\gamma)=\sqrt{1-\frac{g \Delta h}{2 V_{c}^{2}}}=\sqrt{\frac{2 V_{c}^{2}-g \Delta h}{2 V_{c}^{2}}} .
$$

From $\triangle \mathrm{DCD}_{1}$ we are finding

$$
D_{1} D=C D \sin (\alpha+\gamma)=V_{c} \sqrt{\frac{2 \Delta h}{g}} \sqrt{\frac{2 V_{c}^{2}-g \Delta h}{2 V_{c}^{2}}}=\sqrt{\frac{\left(2 V_{c}^{2}-g \Delta h\right) \Delta h}{g}} .
$$

Then parameter $\mathrm{b}_{\mathrm{p}}$ is determining from rule $\frac{b_{n}-b_{p}}{2}=D_{1} D$

where

$$
b_{p}=b_{n}-2 \sqrt{\frac{\left(2 V_{c}^{2}-g \Delta h\right) \Delta h}{g}} .
$$

Taking into account $\triangle \mathrm{OBK}_{1}$ and $\triangle \mathrm{OCK}$, it follows from the geometric scheme that

$$
H_{p}-A B_{1}-\Delta h=K C-B K_{1} \text {, }
$$

but

$$
A B_{1}=\frac{l_{n}}{\operatorname{tg} \gamma},
$$

where $\mathrm{l}_{\mathrm{n}}=\mathrm{BB}_{1}-$ horizontal projection of the generatrix of the rectilinear section $\mathrm{AB}$.

From $\triangle \mathrm{OBK} 1$ and $\triangle \mathrm{OCK}$, on the one hand, it follows that

$$
K C-B K_{1}=R \sin (\alpha+\gamma)-R \sin \gamma .
$$

С учетом (12) и (13) выражение (11) принимает вид

$$
H_{p}-\frac{l_{n}}{\operatorname{tg} \gamma}-\Delta h=R \sin (\alpha+\gamma)-R \sin \gamma .
$$

In view of (12) and (13), expression (11) takes the form

$$
K K_{1}=D_{1} D_{3}=R \cos \gamma-R \cos (\alpha+\gamma),
$$

and

$$
D_{1} D_{3}=O_{1} D-B_{1} B-D_{1} D
$$

In view of (6) and (16), expression (15) takes the form

$$
\frac{\beta_{\Pi}}{2}-\sqrt{\frac{\Delta h\left(2 V_{c}^{2}-g \Delta h\right)}{g}}-l_{\Pi}=R \cos \gamma-R \cos (\alpha+\gamma) .
$$

Thus, we obtain the system of equations (14) and (17) 


$$
\left.\begin{array}{l}
H_{p}-\frac{l_{n}}{\operatorname{tg} \gamma}-\Delta h=R \sin (\alpha+\gamma)-R \sin \gamma \\
\frac{b_{n}}{2}-\sqrt{\frac{\Delta h\left(2 V_{c}^{2}-g \Delta h\right)}{g}}-l_{n}=R \cos \gamma-R \cos (\alpha+\gamma)
\end{array}\right\} .
$$

From the first equation of the system we express $\mathrm{l}_{\mathrm{n}}$ :

$$
l_{n}=\left(H_{P}-\Delta h\right) \operatorname{tg} \gamma-R \operatorname{tg} \gamma[\sin (\alpha+\gamma)-\sin \gamma] .
$$

Substituting (19) into the second equation of system (18), we have

$$
b_{n}-2 \sqrt{\frac{\Delta h\left(2 V_{c}^{2}-g \Delta h\right)}{g}}-2\left(H_{p}-\Delta h\right) \operatorname{tg} \alpha=2 R(\cos \gamma-\cos (\alpha+\gamma)+\operatorname{tg} \gamma[\sin (\alpha+\gamma)-\sin \gamma]) \cdot
$$

From where it follows that

$$
R=\frac{B_{\Pi}-2 \sqrt{\frac{\Delta h\left(2 V_{c}^{2}-g \Delta h\right)}{g}}-2\left(H_{p}-\Delta h\right) \operatorname{tg} \gamma}{2\{\cos \gamma-\cos (\alpha+\gamma)+\operatorname{tg} \gamma[\sin (\alpha+\gamma)-\sin \gamma]\}} .
$$

From $\triangle \mathrm{ABB}$, the length of the rectilinear section $\mathrm{L}_{\mathrm{n}}=\mathrm{AB}$, taking into account (19) and (21), is expressed as follows

$$
L_{n}=\frac{l_{n}}{\sin \gamma}=\frac{H_{p}-\Delta h}{\cos \gamma}-\frac{\left[b_{n}-2 \sqrt{\frac{\Delta h\left(2 V_{c}^{2}-g \Delta h\right)}{g}}-2\left(H_{p}-\Delta h\right) \operatorname{tg} \gamma\right][\sin (\alpha+\gamma)-\sin \gamma]}{2[\cos \gamma-\cos (\alpha+\gamma)] \cos \gamma+\sin \gamma[\sin (\alpha+\gamma)-\sin \gamma]} .
$$

It follows from (7) that

$$
\alpha=\arccos \frac{\sqrt{2 g \Delta h}}{2 V_{c}}-\gamma .
$$

Then the length of the generatrix of the distributor curved area $\mathrm{L \kappa}=\mathrm{BC}$ is determining by the expression

$$
L_{K}=R \alpha=\frac{\left[b_{n}-2 \sqrt{\frac{\Delta h\left(2 V_{c}^{2}-g \Delta h\right)}{g}}-2\left(H_{p}-\Delta h\right) \operatorname{tg} \gamma\right]\left(\arccos \frac{\sqrt{2 g \Delta h}}{2 V_{C}}-\gamma\right)}{2\{\cos \gamma-\cos (\alpha+\gamma)+\operatorname{tg} \gamma[\sin (\alpha+\gamma)-\sin \gamma]\}} .
$$

In view of (8) and (23), the parameter ho is expressed by the following dependence

$$
h_{o}=R \sin (\alpha+\gamma)+\Delta h=\frac{\left[B_{\Pi}-2 \sqrt{\frac{\Delta h\left(2 V_{c}^{2}-g \Delta h\right)}{g}}-2\left(H_{p}-\Delta h\right) \operatorname{tg} \gamma\right] \sqrt{\frac{2 V_{c}^{2}-g \Delta h}{2 V_{c}^{2}}}}{2\{\cos \gamma-\cos (\alpha+\gamma)+\operatorname{tg} \gamma[\sin (\alpha+\gamma)-\sin \gamma]\}}+\Delta h,
$$

and the distance from the distributor axis to the center of curvature of the $\mathrm{BC}$ area (point O) is determined as follows with using dependencies (19) and (21), 


$$
\begin{aligned}
& l_{o}=\left(H_{p}-\Delta h\right) \operatorname{tg} \gamma-R \operatorname{tg} \gamma[\sin (\alpha+\gamma)-\sin \gamma]+R \cos \gamma= \\
& =\left(H_{p}-\Delta h\right) \operatorname{tg} \gamma-\frac{\left[b_{n}-2 \sqrt{\frac{\Delta h\left(2 V_{c}^{2}-g \Delta h\right)}{g}}-2\left(H_{p}-\Delta h\right) \operatorname{tg} \gamma\right][\cos \gamma-\operatorname{tg} \gamma(\sin (\alpha+\gamma)-\sin \gamma)]}{2[\cos \gamma-\cos (\alpha+\gamma)+\operatorname{tg} \gamma(\sin (\alpha+\gamma)-\sin \gamma)]}
\end{aligned}
$$

From $\triangle \mathrm{MD} 2 \mathrm{C}$ we are determining

$$
\delta=\operatorname{arctg} \frac{b_{p}-b_{c}}{2 l_{p}}=\operatorname{arctg} \frac{b_{n}-2 \sqrt{\frac{\left(2 V_{c}^{2}-g \Delta h\right) \Delta h}{g}}-b_{c}}{2 l_{p}} .
$$

\section{Conclusion}

The obtained analytical dependences (4), (7), (10), (19), (21) - (27) are reflected the correlation of the main distributor geometric parameters of the combined coulter for direct strip sowing of cereals with taking into account the particle pass speed from the distributor.

The showing dependencies can be used in the manufacture of test samples of the distributor and the development of methods for its engineering calculation.

\section{Reference}

1. A.Yu. Izmaylov. VIM: 85 years in the forefront of the domestic agricultural machinery engineering. Sel'skokhozyaystvennyye mashiny i tekhnologii, 2014; 6: 10-13. (in Rus.).

2. Izmailov A.Yu., Lobachevsky Y. P., Shaykhov MK, Shaykhov M.M. Grain seeders in a complex of machines for technologies for the restoration of degrading lands // Transactions of GOSNITI. 2017.V. 129. p. 219-228.

3. Skurytin N.F. Energy conservation in direct sowing of grain crops // Actual directions of scientific research of the XXI century: theory and practice. 2014.V.2. N3-4 (8-4). p. 463468.

4. Thompson Carlyle A., Whitney David A. Effects of 30 years of cropping and tillage systems on surface soil test changes // Commun. Soil Sciand Plant Anal. 2000. Vol.31. N12. P. 241257.

5. Keller K. Agriculture without a plow. Preserving tillage and direct sowing // New Agriculture. 2002. No. 1. S. 2226.

6. Brisson, N., Gate, P., Gouache, D., Charmet, G., Oury, F.X. \& Huard, F. (2010). Why are wheat yields stagnating in Europe? A comprehensive data analysis for France. Field Crops Res. 119, 201-212, doi:10.1016/j.fcr.2010.07.012. 